\title{
A survey of urogenital lesions in culled sows (Observations made at the slaughterhouse)
}

\author{
F. MADEC *, J.P. GILLET **, K. IRGENS ** \\ * Ministère de l'Agriculture, Direction de la Qualité, Services vétérincires, \\ Station de Pathologie porcine, F 22440 Ploufragan \\ *:* Laboratoire central de Recherches vétérinaires, \\ 7, rue Curie, F 94700 Maisons-Alfort
}

An investigation was made in 4 slaughterhouses in Brittany (France) from April to June 1981. The genital and the urinary tracts of 1262 sows selected at random were examined. Pyuria was found in 19 p. 100 of the animals. Acute pathological lesions such as haemorrhagic lesions, severe inflammation, Pyuria, Haematuria, and a very thick wall bladder $(>1 \mathrm{~cm})$, were observed in $23 \mathrm{p} .100$ culled sows. Chronic lesions of the urinary tract were found in 20 p. 100 of the sows. Epidemiological aspects of the urinary disorders are discussed.

VI. - ECONOMY

\section{Studies of investment projects and their contribution to the analysis of pig production development}

\author{
C. BRETTE, O. LAPIERRE \\ I.N.A. Paris-Grignon, Département des Sciences animales, \\ Centre d'Etude et de Recherche sur l'Economie et l'Organisation des Productions animales \\ (C.E.R.E.O.P.A.), \\ 16, rue Claude-Bernard, F 75321 Paris Cedex 05
}

The purpose of this work was to show the interest of using studies of projects intended for creation of piggeries in the evaluation of the components of pig production development : combined with the analysis of information pertaining to changes in the production structures, these studies allow to measure the ageing or renovation of the production system and to distinguish between the different schemas of pig farm development. This method has been applied to projects for creation of piggeries in the "Côtes-du-Nord» department between 1974 and 1980 and has led to a better understanding of changes in the techno-economic trends and pig farming structures. During the period considered, 15 p. 100 of the projects were presented by new producers, 37 p. 100 by pig rearers, 4 p. 100 by pig rearers-fatteners and 8 p. 100 by pig fatteners.

The results obtained also allow to forecast future trends in the pig production of a given region and they may lead to a better understanding of the factors of uncertainty.

Thus, for the "Côtes-du-Nord» department the animal average rate of increase in the number of bacon pigs from 1980 to 1990 will most likely exceed that of the sows. According to the hypotheses put forward, this rate should range around 1.6 to $3.6 \mathrm{p}$. 100 per year for bacon pigs and between -0.3 p. 100 and 0.5 p. 100 per year for sows. 